\title{
Increased Prevalence of Sleep Apnea in Children with Pseudohypoparathyroidism Type 1a
}

\author{
Hannah Landreth $^{\mathrm{a}}$ Beth A. Malow ${ }^{\mathrm{b}}$ Ashley H. Shoemaker ${ }^{\mathrm{c}}$ \\ a University of Oklahoma School of Medicine, Norman, Okla., and ${ }^{b}$ Department of Neurology, and \\ 'Division of Endocrinology, Department of Pediatrics, Vanderbilt University, Nashville, Tenn., USA
}

\section{Key Words}

Rare genetic syndromes related to endocrinology .

Pediatric endocrinology $\cdot$ Obesity $\cdot$ Sleep apnea $\cdot$ Sleep

and endocrinology · Albright hereditary osteodystrophy .

Pseudohypoparathyroidism type 1a
$12.8 \pm 5.0$ years, $\mathrm{p}=0.02)$. Conclusions: Children with PHP1a have a 4.4-fold greater relative risk of sleep apnea than similarly obese children. Screening for sleep apnea in this population may be warranted to prevent adverse health outcomes.

(c) 2015 S. Karger AG, Basel

\begin{abstract}
Background/Aims: Pseudohypoparathyroidism type 1a (PHP1a) is a rare genetic disorder. This study aimed to determine the prevalence of sleep apnea in children with PHP1a. Methods: Nineteen patients with PHP1a between the age of 2 and 21 years were enrolled prospectively using online advertisements. Parents completed a medical history and surveys to assess sleep behavior. Polysomnography records were obtained when available. In addition, 18 subjects were identified in a retrospective chart review of de-identified medical records with 2.3 million patient charts. Results: Parents reported sleep disturbance (94\%) and daytime somnolence $(81 \%)$ in their children with PHP1a. In the retrospective chart review, 39\% had a history of sleep apnea versus $8.8 \%$ of a similarly obese control group. In the combined analysis $(n=31), 52 \%$ had a history of snoring and $45 \%$ had a diagnosis of sleep apnea. Patients were obese with a mean BMI zscore of $2.20 \pm 0.59$. Patients with sleep apnea were significantly younger than those without a diagnosis $(8.1 \pm 5.4 \mathrm{vs}$.
\end{abstract}

\section{Introduction}

Pseudohypoparathyroidism is a rare genetic disorder caused by mutations in the gene GNAS which encodes the alpha subunit of the stimulatory G-protein. In some tissues, such as the pituitary, hypothalamus and thyroid, GNAS is imprinted and the maternal allele is preferentially expressed. Maternally inherited mutations therefore lead to the most severe phenotype, known as pseudohypoparathyroidism type 1a (PHP1a). PHP1a is characterized by multi-hormone resistance, obesity, cognitive impairment and the Albright hereditary osteodystrophy (AHO) phenotype. The AHO phenotype is readily identifiable and includes short stature, brachydactyly, round facies and subcutaneous ossifications.

Patients with PHP1a are cared for by pediatric endocrinologists. In order to provide optimal care for these patients, it is critical that we understand the phenotype of

\section{KARGER 125}

(c) 2015 S. Karger AG, Base

1663-2818/15/0841-0001\$39.50/0

E-Mail karger@karger.com

www.karger.com/hrp
Ashley H. Shoemaker, MD, MSCI

2200 Children's Way, DOT 11133

Nashville, TN 37232-9170 (USA)

E-Mail Ashley.H.Shoemaker@vanderbilt.edu 
PHP1a and appropriately manage all comorbidities. Children with PHP1a typically have early-onset obesity and may be at high risk for obesity related comorbidities. Based on the clinical observation of frequent sleep apnea in this population, this study aimed to determine the prevalence of sleep apnea in children with PHP1a. In order to accomplish this aim, we conducted a prospective study of children with PHP1a using a sleep quality survey and medical record review. In addition, we conducted a retrospective chart review of all patients treated for PHP1a at a single institution.

\section{Methods}

\section{Participants}

Study participants with PHP1a were recruited from the Vanderbilt University adult and pediatric endocrinology clinics and online advertisements (www.facebook.com/pseudohypoparathyroidism) from April to August 2014. Inclusion criteria were age $\geq 2$ years old and English proficiency. Informed consent or parental consent and age-appropriate assent were obtained prior to enrollment. The study was approved by the Institutional Review Board of Vanderbilt University.

The retrospective chart review utilized the Vanderbilt University Synthetic Derivative, a de-identified electronic medical record containing approximately 2.3 million patient records updated through August 31, 2013. This was reviewed by the Institutional Review Board of Vanderbilt and determined to be non-human subject research. Patients were included if they had a diagnosis of PHP1a and had at least 1 visit in the pediatric endocrinology clinic, as determined by manual chart review.

\section{Experimental Procedure}

Study data were collected using REDCap (Research Electronic Data Capture) [1] online surveys hosted at Vanderbilt University. All participants completed a medical history form. Participants who reported a history of polysomnography were asked to provide copies of the polysomnography reports to research personnel.

Parents of children less than 18 years old completed an abbreviated version of the Children's Sleep Habits Questionnaire (CSHQ; see www.karger.com/doi/10.1159/000381452 for all online suppl. material). The original CSHQ included 33 items [2]. The abbreviated version used in our study included 18 items graded on a $1-5$ scale $(1=$ always, $5=$ never $)$. This version was developed by the University of Wisconsin, Madison, Wis., USA, as part of the National Institute of Child Health and Human Development Study of Early Child Care and Youth Development.

The Vanderbilt University Synthetic Derivative was searched for records containing a parathyroid hormone level and the keywords 'pseudohypoparathyroidism' or 'Albright hereditary osteodystrophy'. A diagnosis was confirmed by a manual review of the chart. We recorded demographic information, number of clinic visits, history of growth hormone treatment, history of asthma, history of snoring, polysomnography records, diagnosis of sleep apnea and use of CPAP or BiPAP. The BMI z-score was calculated
Table 1. Baseline characteristics of patients with PHP1a

\begin{tabular}{lcll}
\hline & $\begin{array}{l}\text { Prospective } \\
\text { study } \\
(\mathrm{n}=19)\end{array}$ & $\begin{array}{l}\text { Retrospec- } \\
\text { tive study } \\
(\mathrm{n}=18)\end{array}$ & $\begin{array}{l}\mathrm{p} \\
\text { value }\end{array}$ \\
\hline Age, years & $10.4 \pm 5.2$ & $11.1 \pm 5.5$ & 0.69 \\
Race, \% Caucasian & 100 & 94 & 0.23 \\
Gender, \% female & 68 & 72 & 1.00 \\
BMI z-score & $2.24 \pm 0.60$ & $2.26 \pm 0.53$ & 0.92 \\
& $(\mathrm{n}=16)$ & $(\mathrm{n}=16)$ & \\
Asthma, \% affected & 32 & 50 & 0.33 \\
Growth hormone, \% on & 11 & 11 & 1.00 \\
$\quad$ treatment & 53 & 50 & 1.00 \\
Snoring, \% affected & 58 & 39 & 0.33 \\
Sleep apnea, \% affected & & & \\
\hline
\end{tabular}

Data expressed as mean \pm SD unless otherwise specified. Continuous variables were compared using a Student's t test. Categorical variables were compared using a Fisher's Exact test. BMI $\mathrm{z}$-scores were calculated as SDs from the mean using gender and age specific Centers for Disease Control growth charts.

from the height and weight at the most recent endocrine clinic visit. For a comparison group, we also estimated the prevalence of obstructive sleep apnea in children $0-21$ years old with a BMI > 30 based on the presence of either an ICD9 code for sleep apnea (327.2, 327.20 and 327.23) or the keywords 'sleep apnea' or 'OSA' in the medical record problem list.

\section{Statistics}

For the analysis of the 2 groups combined, we excluded the Vanderbilt University patients enrolled in the prospective study as their results were likely duplicated in the de-identified medical records of the retrospective chart review. Results are presented as mean \pm standard deviation. Continuous variables were compared using Student's t test. Categorical variables were compared using Fisher's Exact test. Statistics were performed using the SPSS version 22 .

\section{Results}

\section{Prospective Study}

Nineteen patients between the age of 2 and 21 years enrolled in the prospective study, including 6 males and 13 females. Baseline characteristics are detailed in table 1 . The average age was $10.4 \pm 5.2$ years (range 2-21 years). All patients were currently treated with levothyroxine, calcium and calcitriol. Two males were currently treated with growth hormone. Six patients (2 males and 4 females) had a history of asthma. The patients were obese with a mean BMI z-score of $2.24 \pm 0.60(\mathrm{n}=16)$. 
Habitual snoring was reported in 10 of 19 patients (53\%). Fourteen patients had undergone polysomnography for an evaluation of sleep apnea, and 11 were diagnosed with sleep apnea. Five patients were currently using CPAP or BiPAP for the treatment of sleep apnea. Out of the 5 patients who had not been formally evaluated for sleep apnea, 2 reported habitual nighttime snoring. Fourteen children had undergone polysomnography, and records were obtained from 9 children. Review of these records showed that 2 patients had no significant apnea, 1 patient had central and obstructive apnea, 3 patients had central apnea only, and 3 patients had obstructive apnea only. Sleep architecture was disrupted in 5 children with an increased NREM stage 1 sleep, decreased REM sleep and prolonged REM latency. The obstructive apnea was moderate to severe (pre-treatment Apnea Hypopnea Index $>5$ ). The patients with obstructive apnea all had adenotonsillectomy without any resolution of symptoms; 3 out of 4 children continued to require CPAP or BiPAP postoperatively.

\section{Children's Sleep Habits Questionnaire}

Sixteen parents completed the CSHQ on behalf of their child. The average total score was $2.1 \pm 0.4$ (range 1.43.2). There was no significant difference in total score between unaffected children $(n=6)$, children with sleep apnea not currently treated $(n=5)$, and children treated with CPAP or BiPAP $(n=5)(2.0 \pm 0.3$ vs. $2.01 \pm 0.2$ vs. $2.2 \pm 0.6, \mathrm{p}=0.74$ by one-way ANOVA). Three questions had average scores of $>3$; a score of 3 means symptoms occur 2-4 times per week, and a score of 4 means symptoms occur 5-6 times per week. The highest scoring questions include 'child is restless and moves a lot during sleep' $(3.8 \pm 1.0)$, 'child awakens once during the night' $(3.0 \pm 1.4)$ and 'child seems tired during the daytime' (3.1 \pm 1.3 ). Fifteen of sixteen children (94\%) had scores of $\geq 3$ in the area of sleep disturbance, and 13 of 16 (81\%) had scores of $\geq 3$ for daytime somnolence. The children slept an average of $10.3 \pm 0.9 \mathrm{~h}$ on weeknights and $11.4 \pm 1.1 \mathrm{~h}$ on weekends. Three children, 2-4 years old, napped $2 \mathrm{~h}$ per day, a 6-year-old child napped $1.5 \mathrm{~h}$ per day, and a 7 -year-old child napped $0.5 \mathrm{~h}$ per day.

\section{Retrospective Chart Review}

The Synthetic Derivative search identified 145 charts (out of 2.3 million) for manual review. Eighteen patients were identified with a diagnosis of PHP1a for an overall prevalence of 1 in 125,000 patients. Patients had an average of $10.3 \pm 7.1$ (range 1-25) endocrine clinic visits available for review. There were no significant differenc- es between the prospective and retrospective cohorts. Baseline characteristics are described in table 1. The patients were an average of $11.1 \pm 5.5$ years old (range $2-21$ years) at the time of the last clinic visit. Two females had been treated with growth hormone prior to reaching their final adult height. Half of the patients had a history of asthma. Patients were obese with an average BMI of $31.8 \pm 8.5(\mathrm{n}=17)$ and a BMI $\mathrm{z}$-score of $2.26 \pm 0.53(\mathrm{n}=$ 16). One 30-month-old patient did not have a height recorded, but the weight $\mathrm{z}$-score was 4.11 . Another patient was 17 months old at the last visit with a weight $\mathrm{z}$-score of 2.01 (cannot calculate BMI z-score for children $<2$ years old).

Half of the patients had a history of snoring noted in the medical record. Eight patients had adenoidectomy \pm tonsillectomy for symptoms of sleep apnea. Nine patients had undergone polysomnography for an evaluation of sleep apnea, and 7 were diagnosed with clinically significant sleep apnea. Six were noted to have a disrupted sleep architecture, particularly decreased REM and prolonged REM latency. Four patients had a documented use of CPAP or BiPAP for the treatment of sleep apnea despite a previous adenotonsillectomy. In the synthetic derivative, 28,340 children between 2 and 21 years old have a $\mathrm{BMI}>30$. Of those children, 2,500 had a diagnosis of obstructive sleep apnea based on our search terms; therefore the estimated prevalence of obstructive sleep apnea in obese children was $8.8 \%$. In the same database, the prevalence of sleep apnea in children with PHP1a was $39 \%$. The relative risk of sleep apnea was 4.4 -fold greater in children with PHP1a compared to other obese children at our institution.

\section{Combined Analysis}

Thirty-one subjects were included in the combined analysis of the prospective and retrospective studies as data from Vanderbilt University patients were only included once. The baseline characteristics of the combined group are detailed in table 2 . The average age was $10.7 \pm$ 5.6 years old. Twelve patients (39\%) had a diagnosis of asthma. Sixteen patients (52\%) had a history of snoring, and 14 patients (45\%) had a diagnosis of sleep apnea. Children diagnosed with sleep apnea were significantly younger than those without a diagnosis $(8.1 \pm 5.4$ vs. 12.8 \pm 5.0 years, $p=0.02$ ). There was no significant difference in gender, the BMI z-score or the growth hormone treatment between groups (table 3). Children with sleep apnea were more than twice as likely to have been diagnosed with asthma, but this did not reach statistical significance ( 57 vs. $24 \%, p=0.08$ ). 
Table 2. Baseline characteristics of all patients in the combined analysis $(\mathrm{n}=31)$

Age, years

Race, \% Caucasian

Gender, \% female

BMI z-score

Asthma, \% affected

Growth hormone, \% on treatment

Snoring, \% affected

Sleep apnea, \% affected

Data expressed as mean \pm SD unless otherwise specified. BMI $\mathrm{z}$-scores were calculated as SDs from the mean using gender and age specific Centers for Disease Control growth charts.

Table 3. Combined analysis of all patients with and without sleep apnea

\begin{tabular}{lcll}
\hline & $\begin{array}{l}\text { No sleep } \\
\text { apnea } \\
(\mathrm{n}=17)\end{array}$ & $\begin{array}{l}\text { Sleep apnea } \\
(\mathrm{n}=14)\end{array}$ & $\begin{array}{l}\mathrm{p} \\
\text { value }\end{array}$ \\
\hline Age, years & $12.8 \pm 5.0$ & $8.1 \pm 5.4$ & 0.02 \\
$\begin{array}{l}\text { Gender, \% female } \\
\text { Asthma, \% affected }\end{array}$ & 82 & 50 & 0.12 \\
$\begin{array}{l}\text { Growth hormone, } \\
\text { \% on treatment }\end{array}$ & 24 & 57 & 0.08 \\
$\begin{array}{l}\text { BMI Z-score } \\
\text { (12) }\end{array}$ & $\begin{array}{l}2.07 \pm 0.14 \\
(\mathrm{n}=15)\end{array}$ & $\begin{array}{l}2.38 \pm 0.65 \\
(\mathrm{n}=11)\end{array}$ & 0.19 \\
\hline
\end{tabular}

Data expressed as mean \pm SD unless otherwise specified. Continuous variables were compared using Student's t test. Categorical variables were compared using Fisher's Exact test. BMI $\mathrm{Z}$-scores were calculated as SDs from the mean using gender- and age-specific Centers for Disease Control growth charts.

\section{Discussion}

To our knowledge, this is the first report on sleep apnea in PHP1a. We found an unusually high prevalence of patients with sleep apnea as diagnosed by polysomnography. Sleep apnea is reported in 1-5\% of otherwise healthy children versus $45 \%$ of children with PHP1a in our combined analysis [3, 4]. Habitual snoring is a sensitive, but less specific marker of obstructive sleep apnea in children. Several patients with PHP1a, who had not been formally evaluated for sleep apnea, reported habitual snoring, and further evaluation may reveal an even higher prevalence of apnea in this population.

Obstructive sleep apnea is much more common in obese children with a reported prevalence of $5-8 \%$ for moderate-to-severe apnea (Apnea Hypopnea Index $>5$ ) $[5,6]$; however, we found a 4.4 -fold increase in the relative risk of sleep apnea in children with PHP1a compared with similarly obese children. The high rate of sleep apnea in children with PHP1a (45\%) is only partially attributable to the concomitant obesity. All patients were obese, and there was not a significant difference in the severity of obesity between those with and without a diagnosis of sleep apnea. In addition, obesity does not explain the cases of central sleep apnea found in our cohort as central sleep apnea may be less common in obese children [7]. It is not clear why the children with sleep apnea were significantly younger than those without a diagnosis of sleep apnea. One possibility is that pediatricians now have an increased awareness of sleep apnea due to the obesity epidemic and are more commonly screening for symptoms. Younger children are followed more closely by pediatricians and there may be more opportunities to elicit symptoms. Asthma is associated with the risk of developing obstructive sleep apnea in the general population [8], and the majority of patents with PHP1a and sleep apnea also carried a diagnosis of asthma.

It is possible that sleep apnea and sleep disordered breathing is another clinical manifestation of PHP1a. PHP1a occurs due to inactivating mutations in GNAS and the resultant abnormal $\mathrm{G}_{\mathrm{s}}$-protein coupled receptor signaling. In the murine model, Gnas overexpression inhibits REM sleep and under expression, as seen in PHP1a, may be similarly disruptive to normal sleep architecture. Disruption of sleep architecture may contribute to the daytime somnolence and restless sleep reported by these patients [9]. The neuromuscular phenotype has not been investigated, but children with PHP1a have significant gross and fine motor milestone delays requiring physical and occupational therapy (unpubl. data). Hypotonia in this population may also contribute to development of obstructive sleep apnea.

Excessive daytime sleepiness, untreated sleep apnea and sleep disordered-breathing, as reported in our cohort, is associated with poor memory and concentration $[10,11]$. Treatment of sleep disordered breathing and sleep apnea may improve attention and school performance [12-14]. Diagnosis and treatment of sleep apnea may be particularly beneficial for children with PHP 1a, as the majority have baseline cognitive impairment and school difficulties [15]. Obstructive sleep apnea is associated with an increased risk of heart disease and may alter glucose metabolism [16]. These associations are concerning for patients with PHP1a as the disease is known to cause early-onset obesity and insulin resistance $[17,18]$. 
Our study was limited by the small sample size. It is possible that there was selection bias with patients more likely to participate in the prospective study if they had a diagnosis of sleep apnea. In addition, the sleep apnea prevalence of $39 \%$ in our retrospective cohort may be artificially low as 5 of the patients had $\leq 3$ visits to our clinics, and a pediatric endocrinologist may not address sleep disorders at a routine appointment.

Children with PHP1a may require treatment with growth hormone due to resistance to growth-hormonereleasing hormone. In the Prader-Willi syndrome, treatment with a growth hormone has been associated with fatal obstructive sleep apnea possibly due to increased adenotonsillar hypertrophy or concurrent respiratory infections [19]. While adenotonsillectomy did not resolve obstructive sleep apnea in the majority of our cohorts, similarly high rates of treatment failure have been seen in children with common obesity [20]. CPAP and BiPAP, however, were effective treatments in our cohorts and should be considered before initiating growth hormone therapy.

In summary, we found an increased prevalence of sleep apnea in PHP1a compared with similarly obese children. Early detection and intervention for sleep apnea could improve the quality of life and prevent adverse health outcomes in this vulnerable population.

\section{Acknowledgements}

H.L. was supported by the Vanderbilt Short Term Research Training Program for Medical Students (NIH grant DK007373) and the Vanderbilt Diabetes Research and Training Center (NIH grant DK20593). A.H.S. was supported by the National Institute of Diabetes and Digestive and Kidney Diseases award number K23DK101689 and the CTSA award number KL2TR000446, and REDCap is supported by the CTSA award number UL1TR00445 from the National Center for Advancing Translational Sciences. The contents of this paper are solely the responsibility of the authors and do not necessarily represent the official views of the NIH.

\section{References}

1 Harris PA, Taylor R, Thielke R, Payne J, Gonzalez N, Conde JG: Research electronic data capture (REDCap)-a metadata-driven methodology and workflow process for providing translational research informatics support. J Biomed Inform 2009;42:377-381.

2 Owens JA, Spirito A, McGuinn M: The Children's Sleep Habits Questionnaire (CSHQ): psychometric properties of a survey instrument for school-aged children. Sleep 2000;23: 1043-1051.

-3 Rosen CL, Larkin EK, Kirchner HL, Emancipator JL, Bivins SF, Surovec SA, Martin RJ, Redline S: Prevalence and risk factors for sleep-disordered breathing in 8- to 11-yearold children: association with race and prematurity. J Pediatr 2003;142:383-389.

-4 Bixler EO, Vgontzas AN, Lin HM, Liao D, Calhoun S, Vela-Bueno A, Fedok F, Vlasic V, Graff G: Sleep disordered breathing in children in a general population sample: prevalence and risk factors. Sleep 2009;32:731-736.

5 Verhulst SL, Schrauwen N, Haentjens D, Suys B, Rooman RP, Van Gaal L, De Backer WA, Desager KN: Sleep-disordered breathing in overweight and obese children and adolescents: prevalence, characteristics and the role of fat distribution. Arch Dis Child 2007;92: 205-208.

-6 Alonso-Alvarez ML, Cordero-Guevara JA, Teran-Santos J, Gonzalez-Martinez M, Jurado-Luque MJ, Corral-Penafiel J, Duran-Cantolla J, Kheirandish-Gozal L, Gozal D: Obstructive sleep apnea in obese communitydwelling children: the NANOS study. Sleep 2014;37:943-949.
7 Chou CH, Kang KT, Weng WC, Lee PL, Hsu WC: Central sleep apnea in obese children with sleep-disordered breathing. Int J Obes (Lond) 2014;38:27-31.

8 Teodorescu M, Barnet JH, Hagen EW, Palta M, Young TB, Peppard PE: Association between asthma and risk of developing obstructive sleep apnea. JAMA 2015;313:156164.

-9 Lassi G, Ball ST, Maggi S, Colonna G, Nieus T, Cero C, Bartolomucci A, Peters J, Tucci V: Loss of Gnas imprinting differentially affects REM/NREM sleep and cognition in mice. PLoS Genet 2012;8:e1002706.

10 Djonlagic I, Guo M, Matteis P, Carusona A, Stickgold R, Malhotra A: Untreated sleep-disordered breathing: links to aging-related decline in sleep-dependent memory consolidation. PloS One 2014;9:e85918.

11 Bucks RS, Olaithe M, Eastwood P: Neurocognitive function in obstructive sleep apnoea: a meta-review. Respirology 2013;18:61-70.

12 Biggs SN, Vlahandonis A, Anderson V, Bourke R, Nixon GM, Davey MJ, Horne RS: Long-term changes in neurocognition and behavior following treatment of sleep disordered breathing in school-aged children. Sleep 2014;37:77-84.

13 Kushida CA, Nichols DA, Holmes TH, Quan SF, Walsh JK, Gottlieb DJ, Simon RD Jr, Guilleminault C, White DP, Goodwin JL, et al: Effects of continuous positive airway pressure on neurocognitive function in obstructive sleep apnea patients: The Apnea Positive Pressure Long-term Efficacy Study (APPLES). Sleep 2012;35:1593-1602.
14 Kylstra WA, Aaronson JA, Hofman WF, Schmand BA: Neuropsychological functioning after CPAP treatment in obstructive sleep apnea: a meta-analysis. Sleep Med Rev 2013; 17:341-347.

15 Mouallem M, Shaharabany M, Weintrob N, Shalitin S, Nagelberg N, Shapira H, Zadik Z, Farfel Z: Cognitive impairment is prevalent in pseudohypoparathyroidism type Ia, but not in pseudopseudohypoparathyroidism: possible cerebral imprinting of Gsalpha. Clin Endocrinol (Oxf) 2008;68:233-239.

16 Attal P, Chanson P: Endocrine aspects of obstructive sleep apnea. J Clin Endocrinol Metab 2010;95:483-495.

17 Long DN, McGuire S, Levine MA, Weinstein LS, Germain-Lee EL: Body mass index differences in pseudohypoparathyroidism type la versus pseudopseudohypoparathyroidism may implicate paternal imprinting of Galpha(s) in the development of human obesity. J Clin Endocrinol Metab 2007;92:1073-1079.

18 Muniyappa R, Warren MA, Zhao X, Aney SC, Courville AB, Chen KY, Brychta RJ, Germain-Lee EL, Weinstein LS, Skarulis MC: Reduced insulin sensitivity in adults with pseudohypoparathyroidism type 1a. J Clin Endocrinol Metab 2013;98:E1796-E1801.

19 Miller J, Wagner M: Prader-Willi syndrome and sleep-disordered breathing. Pediatr Ann 2013;42:200-204.

20 Costa DJ, Mitchell R: Adenotonsillectomy for obstructive sleep apnea in obese children: a meta-analysis. Otolaryngol Head Neck Surg 2009;140:455-460. 